\title{
Assessing the dynamics of bifurcation transformations in the economy
}

\author{
Tetyana Vasilyeva ${ }^{1}$, Olha Kuzmenko, ${ }^{1, *}$, Victoria Bozhenko ${ }^{1}$, and Olena Kolotilina $^{1}$ \\ ${ }^{1}$ Sumy State University, Sumy, Ukraine
}

\begin{abstract}
The current global economy faces pivotal changes in the system of its organization, which are essentially transforming relations between economic agents, government institutions, and the population of a particular country. Therefore, the study aims to quantitatively assess the level of transformations in the social, economic and political development of some European countries (Ukraine, France, Italy) using bifurcation theory for the period of 2000-2017. The proposed scientific and methodological approach to assessing the level of transformations in the social, economic and political development of a particular country involves the step-wise implementation: 1) the formation of an information base for the study, which involves collecting and testing statistical data for anomaly detection using the Irwin method, and selecting relevant indicators affecting the social, political and economic situation based on the principal component analysis; 2) the normalization of indicators of the political, economic and social situation using the Harrington's approach; 3 ) the formation of integral indicators of the social, political and economic situation in the country based on the convolution of normalized indicators; 4) the determination of the dynamic properties of the social, political and economic situation in the country by constructing differential equations, which allows determining the existence of a bifurcation type (saddle, focus, node). The empirical study has shown that the indicator of stability of the political and social sphere of Italy was in disequilibrium and was subject to constant fluctuations. At the same time, the stability indicator of the social and economic component of Italy is characterized by an unstable state; and the external influence of negative factors will lead the system to imbalance. In Ukraine there is a stable political and economic and socioeconomic state of the system, i.e. negative impacts will lead the system to equilibrium and further positive development according to the components of the country. The development of the political and social sphere is characterized by the equilibrium state, and continues to develop according to the acquired tendency. The resulting methodological and practical developments will serve as a guide for the state authorities of the respective country for adjusting current macroeconomic policies and developing strategic plans for social and economic development.
\end{abstract}

\section{Introduction}

The defining features of the current development of the global economy is the rapid and significant transformation of most spheres of public life, which is due to the deepening of integration processes between countries, the free movement of capital and labor force, the rapid development of information technologies and innovations, as well as dramatic sociocultural shifts, etc. These structural changes in the global space provoke a number of shifts in national economic systems. Under these conditions, countries face new potential opportunities, growing risks and problems associated with the extensive development of the national economy, inefficient use of natural resources, uneven distribution of income between population groups, and the possible and increasing unauthorized use of personal data both in economic and political spheres. Thus, the study of bifurcation patterns in the functioning of the social, economic, and political system of a country is relevant and promising.

\section{Literature Review}

The issue of studying the relationship between economic, political and social processes in a country is widely reflected in the scientific literature. Despite the significant number of publications on this issue, the development of social, economic and political relations in a particular country is a dynamic process, which constantly requires in-depth research.

Scientific literature studies the influence of political instability on the development of economic and social processes by the example of many countries worldwide. In particular, (Nazeer \& Masih, 2017) evaluated the impact of political instability on foreign direct investment and Malaysian economic growth based on the construction of an auto regressive distributed lag model [1]. Carmignani studied the impact of instability (including political uncertainty) on macroeconomic indicators, namely, on budget revenues, inflationary processes, and the state monetary policy [2].

Moreover, empirical studies (Bhatti, Ali, Nasir, \& Iqbal, 2008) have revealed that political instability and uncertainty have a destructive effect on the processes related to the gross fixed capital formation, while

\footnotetext{
* Corresponding author: okuzmenko84@gmail.com
} 
democracy does not affect the level of private investment [3]. This study was conducted based on Pakistan's statistical data. (Kaplan \& Akçoraoğlu, 2017) assessed the relationship between economic growth and political instability factors (corruption, government instability, internal and external conflicts, religious and ethnic tensions, democratic accountability and quality of bureaucracy) for OECD countries during 1984-2012 [4]. The calculations showed that government stability and internal and external conflicts are an obstacle to rapid economic growth, while democratic accountability, ethnic and religious tension and the quality of bureaucracy do not have a statistically significant impact on the economic growth of the OECD countries.

Ekici \& Koydemir quantified the interconnection between different indicators of social capital (general trust, trust in institutions, political activity, care for others, social rules and membership in volunteer organizations), democracy and welfare of the population [5]. Statistical data on 71 countries worldwide for 1960-1985 (Alesina, Özler, Roubini, \& Swagel, 1996) have shown that the inequality of the income among the population led to an aggravation of social discontent, thereby provoking political instability. At the same time, uncertainty in the political and economic environment is reflected in the reduction of investment in the country [6].

(Kuzmenko \& Roienko, 2017) studied the impact of information technology and innovation on the level of economic well-being of the population (by the example of France, Great Britain, Germany, Italy and Spain), identified probable changes in the distribution of income of the population for the next 15 years, taking into account transformations in the technological and socioeconomic environment caused by the active development of the Industry 4.0 [7].

\section{Methodology}

The proposed scientific and methodological approach to assessing the level of transformations in the social, economic and political development of the country involves the step-wise implementation: first, the formation of an information base of the study, which involves collecting and testing statistical data for anomaly detection using the Irwin method, and selecting relevant indicators affecting the social, political and economic situation based on the principal component analysis; secondly, the normalization of indicators of the political, economic and social situation using the Harrington's approach; thirdly, the formation of integral indicators of the social, political and economic situation in the country based on the convolution of normalized indicators; fourthly, the determination of the dynamic properties of the social, political and economic situation in the country by constructing differential equations, which allows determining the existence of a bifurcation type (saddle, focus, node).

\section{Findings}

The scientific and methodological approach, which consists of four main stages, was designed to assess the level of bifurcation transformations in the social, economic and political development of the country.

The first step implied the formation of an array of indicators based on the World Bank data that allows assessing the social, political and economic status of Ukraine, Italy, and France. The volume of representative indicators of influence on economic development, political status and social sphere is 18 years (2000 to 2017). The following indicators were chosen to characterize the state of the social sphere: government expenditures on the education system, the number of people aged 15-64 years, the unemployment rate, the labor force, the birth rate, refugee population by country or territory of asylum). The following indicators should describe the political situation in the country: military expenditures, the amount of public debt, the proportion of women in the national parliament, general reserves, the amount of income, excluding grants, portfolio equity, net inflows). The economic situation of a country's development can be characterized based on the following indicators: GDP growth rate, the volume of imports of goods and services, the volume of exports of goods and services, gross savings, GDP, gross value added at coefficient value.

The time series for the anomaly detection is tested by the Irwin method [8]. Results of the step revealed that the year 2005 was abnormal for Ukraine, based on the following indicators: GDP growth rate, volume of income, excluding grants, export of goods and services; and social sphere indicator (labor force) for the year 2017. In particular, for Italy and France, 2009 and 2010 were the most abnormal based on the indicators such as GDP growth rate, portfolio equity, net inflows, government expenditures on education system, gross savings, export of goods and services, volume of import of goods and services, unemployment rate, portfolio equity, net inflows; the year 2017 for France (the proportion of women in the national parliament), for Italy (portfolio equity, net inflows).

We apply the principal component analysis to select relevant indicators of influence on the social, political and economic state of each of the analyzed countries [8]. This step has shown that the most significant indicators for Ukraine were the GDP growth rate, the share of women in national parliaments, the export of goods and services, labor force, gross savings, the population aged 15-64, total reserves, and the number of refugees. Indicators of the greatest impact on the economic and political situation in Italy and France are the GDP growth, the share of women in national parliaments, exports of goods and services, military expenditures, general reserves, imports of goods and services, income, excluding grants, public debt. Relevant indicators of Italy's social sphere (government expenditures on education, population aged 15-64, birth rate, unemployment, labor force, refugee population); for France (unemployment, government expenditures on education, labor force). 
Second step. Normalization of the indicators of political status, economic development, social sphere was carried out based on the Harrington's approach. The application of this approach is necessary to convert the size of the indicators (normalization), i.e. the conversion of the values of indicators $\left(Y_{i}\right)$ into dimensionless values $\left(d_{i}\right)$ - the desirability function.

This method requires to consider E. Harrington's analytic function $d_{i}=\exp \left(-\exp \left(-Y_{i}\right)\right)$, where $Y_{i}-$ an indicator characterizing social, economic and political development, in the normal form. The conversion mechanism allows reducing all measurements from zero (poor quality) to one (high quality). The obtained results assess the quality of the indicators of influence on the political situation, social sphere and economic development of countries.

The third step involves the construction of integral indicators of the social, political and economic status of Ukraine, Italy and France, based on the convolution of normalized indicators. The method of calculating the geometric mean of the indicators is used to determine the generalized value of the social, economic and political component. The normalized value of the radius of the circle described is calculated by the formula:

$$
R_{t}=\frac{n_{e t} n_{s t} n_{p t}}{\left(n_{e t}+n_{s t}+n_{p t}\right)\left(-n_{e t}+n_{s t}+n_{p t}\right)\left(n_{e t}-n_{s t}+n_{p t}\right)\left(n_{e t}+n_{s t}-n_{p t}\right)},
$$

where $R_{t}$ - the radius of the described circle of the social, political and economic state of the country (at a given time $t) ; n_{e t}, n_{s t}, n_{p t}-$ normalized generalized indicators of economic, political and social development of the country.

The resulting data are used to form an array of values of integral indicators of the social, political and economic component and the radius of the described circle $\left(R_{t}\right)$ of the countries under study. We provide an example of the calculated integral indicators for Ukraine in the period from 2000 to 2017 (Table 1). Similarly, we create an array of information for further structural modeling and the theory of bifurcation of the stability indicator $\left(R_{t}\right)$ based on the integral indicators of the social sphere, political state and economic development of Italy and France.

The fourth step. The next step implies constructing differential equations, which are used to map the phase trajectories onto the chosen plane of the phase space. The phase portraits of the system of differential equations are constructed in the MathCad program, to determine the sustainability indicator of the social, political and economic status of Ukraine, Italy, and France. This approach is based on bifurcation theory, an analysis of all possible situations on the existence of a bifurcation type (node, saddle, focus).

Differential equations are used to simulate the social, economic, and political stability. Such dependencies describe the state of the dynamic system and its nature. The right-hand side of the equation, which in itself binds independent variables, is of particular importance. We consider the equation in terms of each component of the social, political and economic state of Ukraine, Italy, and France. Such equations establish relations between independent variables (ec, $p, s$ - economic, political, social component), function ( $R(e c), R(p), R(s)$, where $R_{t}-$ the radius of the described social, political and economic state of the country (at a given time t) and its derivative $\left(\frac{d}{d t} e c, \frac{d}{d t} p, \frac{d}{d t} s\right)$. We develop a system of three differential equations for the country under study (Ukraine, Italy and France), which allows determining the behavior of the phase trajectory of the political, economic, political and social, social and economic indicators of stability.

Table 1. Integral indicators of the social, political and economic component and the radius of the described circle $\left(R_{t}\right)$ for Ukraine.

\begin{tabular}{|c|c|c|c|c|}
\hline Ukraine & $\begin{array}{c}\text { Economic } \\
\text { component }\end{array}$ & $\begin{array}{c}\text { Political } \\
\text { component }\end{array}$ & $\begin{array}{c}\text { Social } \\
\text { component }\end{array}$ & $\begin{array}{c}R_{t} \text { (radius of } \\
\text { the described } \\
\text { circle) }\end{array}$ \\
\hline 2000 & 0.636 & 0.427 & 0.539 & 0.322 \\
\hline 2001 & 0.622 & 0.438 & 0.526 & 0.316 \\
\hline 2002 & 0.612 & 0.411 & 0.524 & 0.310 \\
\hline 2003 & 0.645 & 0.433 & 0.514 & 0.323 \\
\hline 2004 & 0.687 & 0.411 & 0.502 & 0.346 \\
\hline 2005 & 0.616 & 0.453 & 0.522 & 0.315 \\
\hline 2006 & 0.546 & 0.510 & 0.520 & 0.304 \\
\hline 2007 & 0.530 & 0.591 & 0.591 & 0.331 \\
\hline 2008 & 0.517 & 0.587 & 0.638 & 0.339 \\
\hline 2009 & 0.485 & 0.563 & 0.636 & 0.330 \\
\hline 2010 & 0.496 & 0.592 & 0.595 & 0.327 \\
\hline 2011 & 0.525 & 0.583 & 0.526 & 0.316 \\
\hline 2012 & 0.460 & 0.590 & 0.480 & 0.302 \\
\hline 2013 & 0.415 & 0.571 & 0.494 & 0.293 \\
\hline 2014 & 0.426 & 0.540 & 0.479 & 0.282 \\
\hline 2015 & 0.458 & 0.583 & 0.455 & 0.297 \\
\hline 2016 & 0.485 & 0.595 & 0.422 & 0.301 \\
\hline 2017 & 0.517 & 0.619 & 0.392 & 0.311 \\
\hline
\end{tabular}

$$
\left\{\begin{array}{l}
\frac{d}{d t} e c=1.419 \cdot e c^{2}-0.6352 \cdot p \cdot s \\
\frac{d}{d t} p=0.7274 \cdot p-0.6352 \cdot e c \cdot s \\
\frac{d}{d t} s=1.2504 \cdot s^{2}-0.6352 \cdot e c \cdot p
\end{array}\right.
$$

$$
\left\{\begin{array}{l}
\frac{d}{d t} e c=2.0588 \cdot e c-2.5236 \cdot p \cdot s \\
\frac{d}{d t} p=1.6688 \cdot p-2.5236 \cdot e c \cdot s \\
\frac{d}{d t} s=\frac{0.364}{s^{2}}-2.5236 \cdot e c \cdot p
\end{array}\right.
$$

$$
\left\{\begin{array}{l}
\frac{d}{d t} e c=1.4142 \cdot e c^{2}-0.6848 \cdot p \cdot s \\
\frac{d}{d t} p=1.3044 \cdot p^{2}-0.6848 \cdot e c \cdot s \\
\frac{d}{d t} s=0.7456 \cdot s-0.6848 \cdot e c \cdot p
\end{array}\right.
$$

Mathematical software Mathcad, based on the system of differential equations, formalizes for each country (Ukraine, Italy and France) the phase structure - the 
stability indicator of the social, political and economic state of the country. We provide an example of the phase structure of Ukraine, built according to the system data (2). This model (5) analytically describes the state of the stability indicator of the social sphere, the political state and economic development of the country in the period from 2000 to 2017. Similarly, we build a phase structure for Italy and France. The mathematical formalization of the phase structure (5) analytically describes the dependence of the stability indicator and serves to construct a phase portrait. The phase portrait graphically interprets the analytical description of the dynamic system of the countries under study and illustrates the dependence of the stability indicator of social, political and economic components on the bifurcation diagram.

$$
\text { Faza } \left.(e c 0, p 0, s 0, d t, N):=\mid \begin{array}{l}
\left(e c_{0} \leftarrow e c 0 ; p_{0} \leftarrow p 0 ; s_{0} \leftarrow s 0\right) \\
f o r, k \in 0 \ldots N \\
f f \leftarrow f\left(e c_{k}, p_{k}, s_{k}\right)
\end{array}\right] \begin{array}{ll}
e c_{k+1} \leftarrow\left\lfloor e c_{k}+d t \cdot\left\lfloor 1.419\left(e c_{k}\right)^{2}+-0.6352 p_{k} \cdot s_{k}\right\rfloor\right. \\
p_{k+1} \leftarrow\left\lfloor p_{k}+d t \cdot\left(0.7274 p_{k}+-0.6352 \cdot e c_{k} \cdot s_{k}\right)\right\rfloor \\
s_{k+1} \leftarrow\left\lfloor s_{k}+d t\left\lfloor 1.2504\left(s_{k}\right)^{2}+-0.6352 \cdot e c_{k} \cdot p_{k}\right\rfloor\right. \\
(e c, p, s)
\end{array}
$$

We consider the behavior of the dynamic system of the stability indicator of Ukraine (Fig. 1). Bifurcation diagram, according to bifurcation theory (Fig. 1 (a), (c)) describes the political and economic and socioeconomic indicators of stability. We can consider a phase portrait (Fig. 1 (a), (c)) for the presence of a bifurcation type of "stable node" with "saddle" elements. This type characterizes a stable political and economic and socioeconomic state of the system, i.e. negative impacts will lead the system to equilibrium and further positive development according to the components of the country. The situation of the political and social phase portrait of Ukraine (Fig. 1 (b)) is partial, of the "node" type with a distinct "saddle" type of bifurcation. The diagram of this dynamic system emphasizes that the political and social state of the stability indicator is ambiguous, and may change under the influence of the stimulus on the process under study.

The study of the phase portrait of Italy demonstrates different types of bifurcation theory. We consider the political and economic phase portrait of the country (Fig. 2 (a)), which has a clearly defined "stable node" type of bifurcation. The system of this type is in equilibrium, and continues to gain positive development under the influence of factors of the environment. We analyze the political and social phase portrait of Italy (Fig. 2 (b)), where we observe a "focus" type of bifurcation. This dynamic system of stability indicators of the political and social sphere has an unstable tendency of development. A significant change in one of the significant indicators or a number of significant values in the phase portrait of the dynamic system lead to qualitative changes, the stability indicator of the political and social sphere of Italy has a tendency to constant dynamics, unstable future development. Thus, the state of the stability indicator of the political and social sphere is in disequilibrium and subject to constant fluctuations.

Now we consider the behavior of phase trajectories on the chosen plane of the socioeconomic component of
Italy. The bifurcation type of the phase portrait is a distinct "saddle" (Fig. 2 (c)).

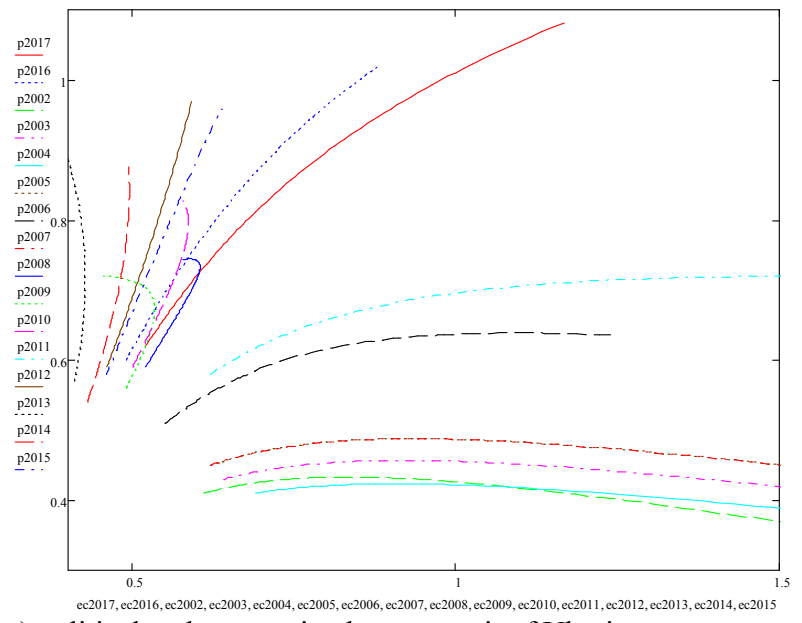

a) political and economic phase portrait of Ukraine

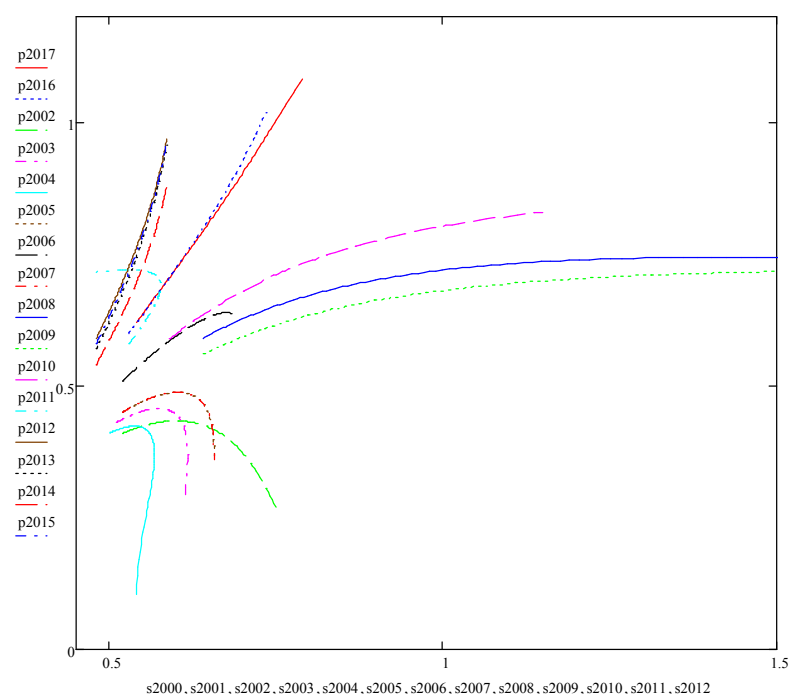

b) political and social phase portrait of Ukraine

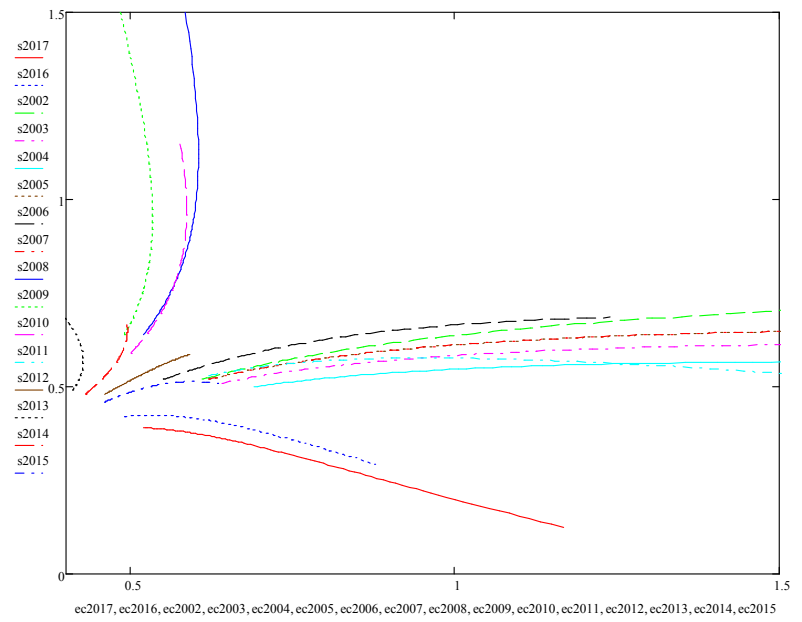

c) social and economic phase portrait of Ukraine

Fig. 1. Phase portrait of the stability indicator of the social, political and economic state of Ukraine.

This indicates a change in the trajectory of the stability indicator, with a significant change in the parameter and a fixed value of another parameter in the social and economic phase portrait of Italy. The bifurcation type 
"saddle" characterizes the dynamic system, which is in a disequilibrium state. When the system parameter of the sustainability indicator changes with time, the system is characterized by a dynamic development of the social and economic sphere. Consequently, the stability indicator of the social and economic component of Italy is characterized as unstable; the external influence of negative factors will lead the system to disequilibrium.

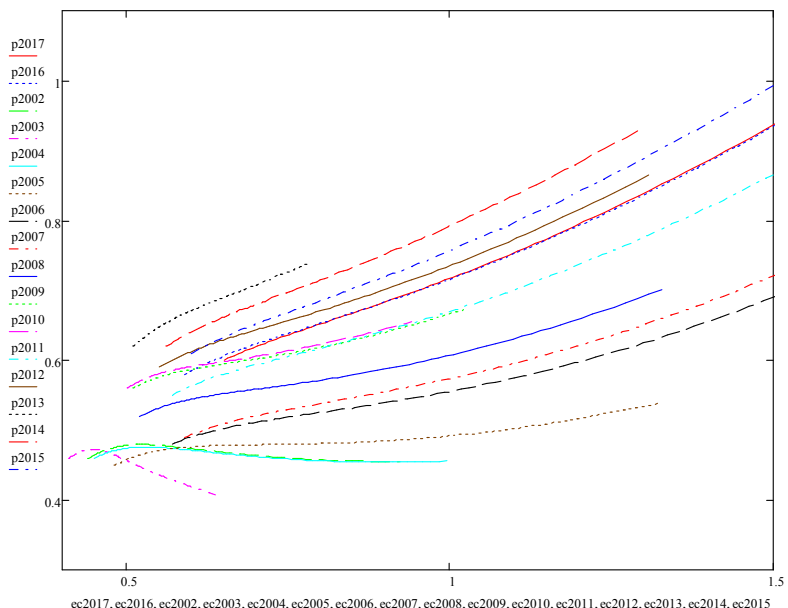

a) political and economic phase portrait of Italy

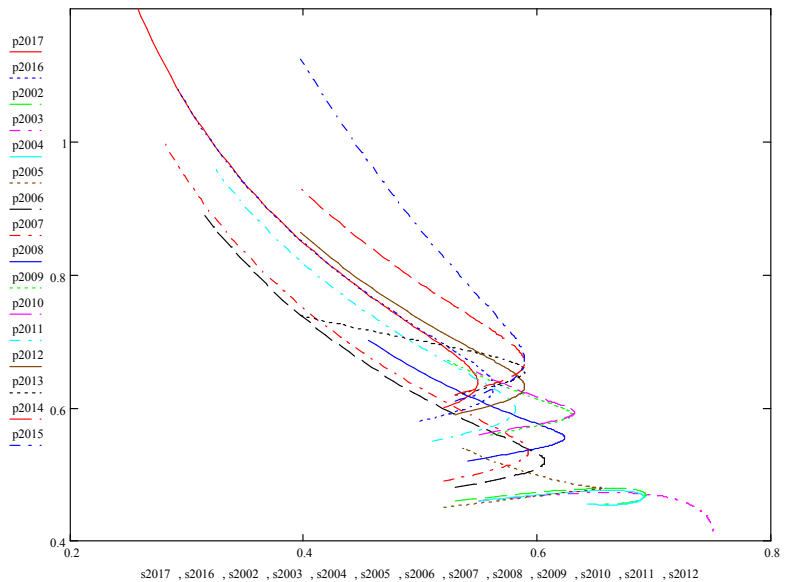

b) political and social phase portrait of Italy

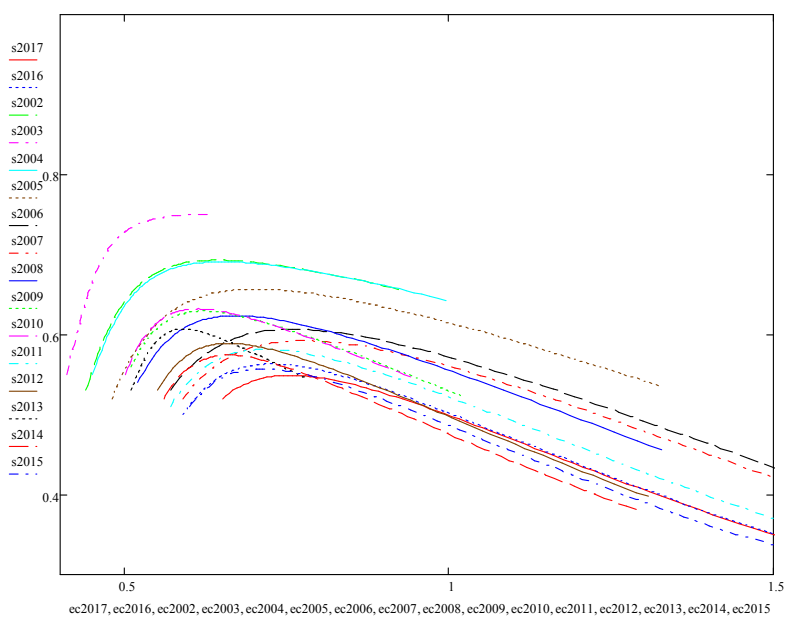

c) social and economic phase portrait of Italy

Fig. 2. Phase portrait of the stability indicator of the social, political and economic situation in Italy.
Figure 3 provides graphic interpretation of the political and social phase portrait of France. The bifurcation type is a combined, distinct "stable node" with "saddle" elements. This dynamic system is characterized by the equilibrium state, under the influence of various factors, the stability indicator is in equilibrium and continues to develop according to the acquired tendency. Similarly, we consider the political and economic, social and economic phase portrait of France. We analyze the states under study to determine the existence of a bifurcation type. There are similar trends in the dynamics of stability indicators, distinct "node" with "saddle" elements. Consequently, the stability indicator of all the components of France has the same bifurcation type and acquires stable development (equilibrium), despite the negative impact of the environment.

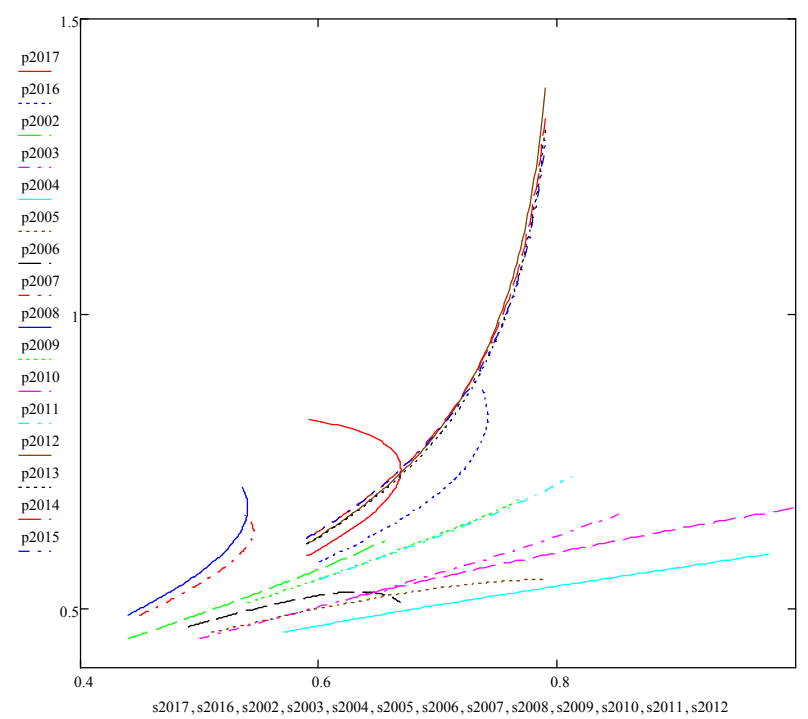

Fig. 3. Phase portrait of the stability indicator of the political and social state of France.

\section{Conclusion}

The study presents a general description of the bifurcation types of the stability indicator of the social, political and economic component of Ukraine, Italy and France. Mathematical modeling of phase portraits according to bifurcation theory implies the following stages: verification of indicators, which allow assessing the social, political and economic state of the countries, for the anomaly detection; normalization of relevant indicators of influence on the analyzed components; construction of integral indicators of the social, economic sphere, political status; study of phase portraits of dynamical systems based on differential equations in relation to each component of Ukraine, Italy and France.

Bifurcation theory is being widely used in economics, the study of economic processes. The phase portrait of the stability indicator of social, political and economic components properly describes the state of the dynamic system, according to bifurcation theory. It allows analyzing the process of further behavior of the dynamic system in the event of a change in the parameter (the influence of environmental variables). 
Funding: This research was funded by the grant from the Ministry of Education and Science of Ukraine (No. s/r 0118U003569).

\section{References}

1. Nazeer, A.M., Masih, M.: Impact of political instability on foreign direct investment and Economic Growth: Evidence from Malaysia. Munch Personal RePEc Archive. https://mpra.ub.unimuenchen.de/79418/1/MPRA_paper_79418.pdf (2017). Accessed 20 Feb 2019

2. Carmignani, F.: Political instability, uncertainty and economics. J. of Econ. Surv. 17, 1-54 (2003). doi:10.1111/1467-6419.00187

3. Bhatti, A.M., Ali, A., Nasir, M., Iqbal, W.: Impact of democracy, political instability and policy uncertainty on private investment: a case study of Pakistan. Form. J. of Econ. Stud. 4, 87-101 (2008)

4. Kaplan, E.A., Akçoraoğlu, A.: Political Instability, Corruption, and Economic Growth: Evidence from a Panel of OECD Countries. Bus. and Econ. Res. J. 8(3), 363-377 (2017). doi:10.20409/beri.2017.55

5. Ekici, T., Koydemir, S.: Social Capital, Government and Democracy Satisfaction, and Happiness in Turkey: A Comparison of Surveys in 1999 and 2008. Soc. Indic. Res. 118(3), 1031-1053 (2014). doi:10.1007/s11205-013-0464-y

6. Alesina, A., Özler, S., Roubini, N., Swagel, P.: Political Instability and Economic Growth. J. of Econ. Gr. 1, 189-211 (1996). doi:10.1007/BF00138862

7. Kuzmenko, O.V., Roienko, V.V.: Nowcasting income inequality in the context of the Fourth Industrial Revolution. Soc. Econ. Chall. 1(1), 5-12 (2017). doi:10.21272/sec.2017.1-01

8. Kuzmenko, O.V, Kolotilina, O.V.: Modeling of estimating of the level of economic, social and political development of Ukraine, Italy and France in the context of optimization their relations. Intern. Scien. and Prod. J. 2(39), 111-120 (2018)

9. Kouba, L., Grochova, L.: Financial Crisis, Elite Political Instability and Economic Growth in Central and Eastern European Countries. In: Stavarek, D., Vodova, P. (eds.) Proceedings of the 13th international conference on finance and banking, Ostrava, Czech Republic, pp. 184-195 (2012)

10. Siermann, C.L.J.: Politics, Institutions and the Economic Performance of Nations. Edward Elgar Publishing, Cheltenham (1998) 